\title{
A CORRECTION TO "ON THE AVERAGE NUMBER OF REAL ROOTS OF A RANDOM ALGEBRAIC EQUATION"
}

M. KAC

Dr. R. P. Boas has kindly called my attention to the fact that the proofs of the results of Littlewood and Offord ${ }^{2}$ have been published in the Proc. Cambridge Philos. Soc. vol. 35 (1939) pp. 133-148. It should also be mentioned that a similar problem was studied by entirely different methods by S. O. Rice in his paper The distribution of the maxima of a random curve, Amer. J. Math. vol. 61 (1939) pp. 409416. Finally, I take this opportunity to state that under the conditions considered in my note the probability that equation (1) has a multiple root is zero. In fact, this probability is the probability that the discriminant vanish; this probability is clearly equal to zero since the discriminant is an analytic function of the coefficients and the measure considered is nonsingular.

\section{Cornell University}

Received by the editors June 9, 1943.

1 Bull. Amer. Math. Soc. vol. 49 (1943) pp. 314-320.

2 See the footnote on page 314 of my note.

\section{A CORRECTION TO "A LINEAR TRANSFORMATION WHOSE VARIABLES AND COEFFICIENTS ARE SETS OF POINTS"}

\author{
S. T. SANDERS, JR.
}

In my paper $A$ linear transformation whose variables and coefficients are sets of points, published in Bull. Amer. Math. Soc. vol. 48 (1942), the fourth line, page 442 , should read: "there is a subscript $k=k^{\prime}$ such that $P_{k^{\prime}}$ involves only factors of $P_{1}$."

SOUTHWESTERN LOUISIANA INSTITUTE

Received by the editors April 14, 1943. 